\title{
Hemithea aestivaria (Hübner) (Lepidoptera: Geometridae), a Palaearctic moth, new to eastern North America
}

\author{
Christian Schmidt ${ }^{\ddagger}$, Alexandre Anctil§

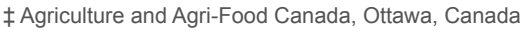 \\ § Centre de données sur le patrimoine naturel du Québec - ministère des Forêts, de la Faune et des Parcs, \\ gouvernement du Québec, Quebec, Canada
}

Corresponding author: Christian Schmidt (christian.schmidt@canada.ca)

Academic editor: Axel Hausmann

Received: 24 Feb 2021 | Accepted: 15 Apr 2021 | Published: 21 May 2021

Citation: Schmidt C, Anctil A (2021) Hemithea aestivaria (Hübner) (Lepidoptera: Geometridae), a Palaearctic moth, new to eastern North America. Biodiversity Data Journal 9: e64985. https://doi.org/10.3897/BDJ.9.e64985

\begin{abstract}
The geometrid moth Hemithea aestivaria (Hübner, 1789) was introduced from Europe to North America, first being detected in British Columbia in 1973. Until 2019, its North American range was limited to a restricted area of the Pacific Northwest. Here, we report on the first records of $\mathrm{H}$. aestivaria for eastern North America from three widely separated urban centres in eastern Canada during 2019-2020.
\end{abstract}

\section{Keywords}

alien species, invasive species, exotic species, Geometrinae, citizen science

\section{Introduction}

Hemithea aestivaria (Hübner, 1789) (Fig. 1) is one of numerous European Lepidoptera species accidentally introduced to North America and, more specifically, one of six geometrids accidentally introduced to the Pacific Northwest Region (Pohl et al. 2016, Pohl et al. 2015Pohl et al. 2018). Three of these species have had separate introductions (of 
independent European origin or from within North America): Operophtera brumata (L.), Pasiphila rectangulata (L.) and Thera juniperata (L.) (Ferguson 1975, Ferguson 1978, Maier 2005). Here we report the first eastern North American records of Hemithea aestivaria (Table 1), which was previously restricted to coastal British Columbia, Canada and adjacent USA.

Table 1.

First records of Hemithea aestivaria for eastern North America.

\begin{tabular}{|l|l|l|l|l|}
\hline Location & Year & Month & Day & Link to observation \\
\hline Durham, Ontario & 2019 & 07 & 8 & $\underline{w w w . i n a t u r a l i s t . o r g / o b s e r v a t i o n s / 28454987}$ \\
\hline Toronto, Ontario & 2020 & 06 & 29 & $\underline{w w}$.inaturalist.org/observations/51445379 \\
\hline Saint-Augustin-de-Desmaures, Québec & 2020 & 06 & 27 & $\underline{w w w . i n a t u r a l i s t . o r g / o b s e r v a t i o n s / 51218465}$ \\
\hline Saint-Augustin-de-Desmaures, Québec & 2020 & 06 & 30 & $\underline{w w w . i n a t u r a l i s t . o r g / o b s e r v a t i o n s / 51851347}$ \\
\hline Saint-Augustin-de-Desmaures, Québec & 2020 & 07 & 1 & $\underline{w w w . i n a t u r a l i s t . o r g / o b s e r v a t i o n s / 52109366}$ \\
\hline Saint-Augustin-de-Desmaures, Québec & 2020 & 07 & 6 & $\underline{w w w . i n a t u r a l i s t . o r g / o b s e r v a t i o n s / 52355700}$ \\
\hline Saint-Augustin-de-Desmaures, Québec & 2020 & 07 & 15 & $\underline{w w w . i n a t u r a l i s t . o r g / o b s e r v a t i o n s / 53333395}$ \\
\hline Saint-Augustin-de-Desmaures, Québec & 2020 & 07 & 24 & $\underline{w w w . i n a t u r a l i s t . o r g / o b s e r v a t i o n s / 54346240}$ \\
\hline Halifax, Nova Scotia & 2020 & 07 & 14 & $\underline{w w w . i n a t u r a l i s t . o r g / o b s e r v a t i o n s / 53499624}$ \\
\hline Halifax, Nova Scotia & 2020 & 07 & 19 & $\underline{w w w . i n a t u r a l i s t . o r g / o b s e r v a t i o n s / 53612983}$ \\
\hline Halifax, Nova Scotia & 2020 & 07 & 20 & $\underline{w w w . i n a t u r a l i s t . o r g / o b s e r v a t i o n s / 53805400}$ \\
\hline Halifax, Nova Scotia & 2020 & 07 & 26 & $\underline{w w w . i n a t u r a l i s t . o r g / o b s e r v a t i o n s / 54574094}$ \\
\hline
\end{tabular}

In Europe, larvae of Hemithea aestivaria feed on a broad diet of deciduous broad-leaved shrubs comprising at least seven different plant families (summarised by Hausmann 2001). In British Columbia, larvae have been recorded from cherry, apple, wild plum and Rubus and Crataegus (Bolte and Munroe 1979). It is not clear to what extent the B.C. hostplant records represent sampling bias, versus a biological preference for spring-flowering Rosaceae shrubs. Early instar larvae of $H$. aestivaria probably feed on the foliage and flowers of a wide variety of non-coniferous shrubs. In Europe and British Columbia, $H$. aestivaria is univoltine and winter diapause is in the early larval instars; it is bivoltine in Japan, exceptionally so in Europe (Hausmann 2001). The flight period in British Columbia is late June to early August. Habitats, rich in deciduous shrubs, are favoured, including mesic forest edges, gardens and parks (Hausmann 2001). No population outbreaks or damage due to defoliation by $H$. aestivaria has been reported from the Pacific Northwest, nor from Europe.

The first North American specimens of $H$. aestivaria were collected in British Columbia in 1973 (Doganlar and Beirne 1979). Ferguson (1985) and Gillespie and Gillespie (1982) erroneously date the first records to 1979 and 1978, respectively (error repeated in Pohl et al. 2015, Mattson et al. 1994), but by that time, $H$. aestivaria was already common in the greater Vancouver area, with at least 40 larval collections from Burnaby, New Westminster 
and Langley (Doganlar and Beirne 1979). Although only documented from the Vancouver area up to 1985 by Ferguson (1985), by 1988, it had spread to eastern Vancouver Island (Taylor Bay, 17 July 1988, G.G. Anweiler, specimen \# UASM59768) (University of Alberta E. H. Strickland Entomological Museum 2021) and it now occurs widely throughout the Georgia Basin (Fig. 2). The range of $H$. aestivaria also expanded southwards into the USA and it is now widespread in the Puget Sound region. On the Pacific coast, it is documented from Pacific County, WA and, in 2020, it was recorded in Oregon for the first time in Clatsop County (www.inaturalist.org/observations/53184678). However, $H$. aestivaria has not expanded into interior British Columbia or Washington east of the Cascade/Coast Range crest since establishment in the early 1970 s and its North American distribution has remained restricted to a small area of the Pacific Northwest.

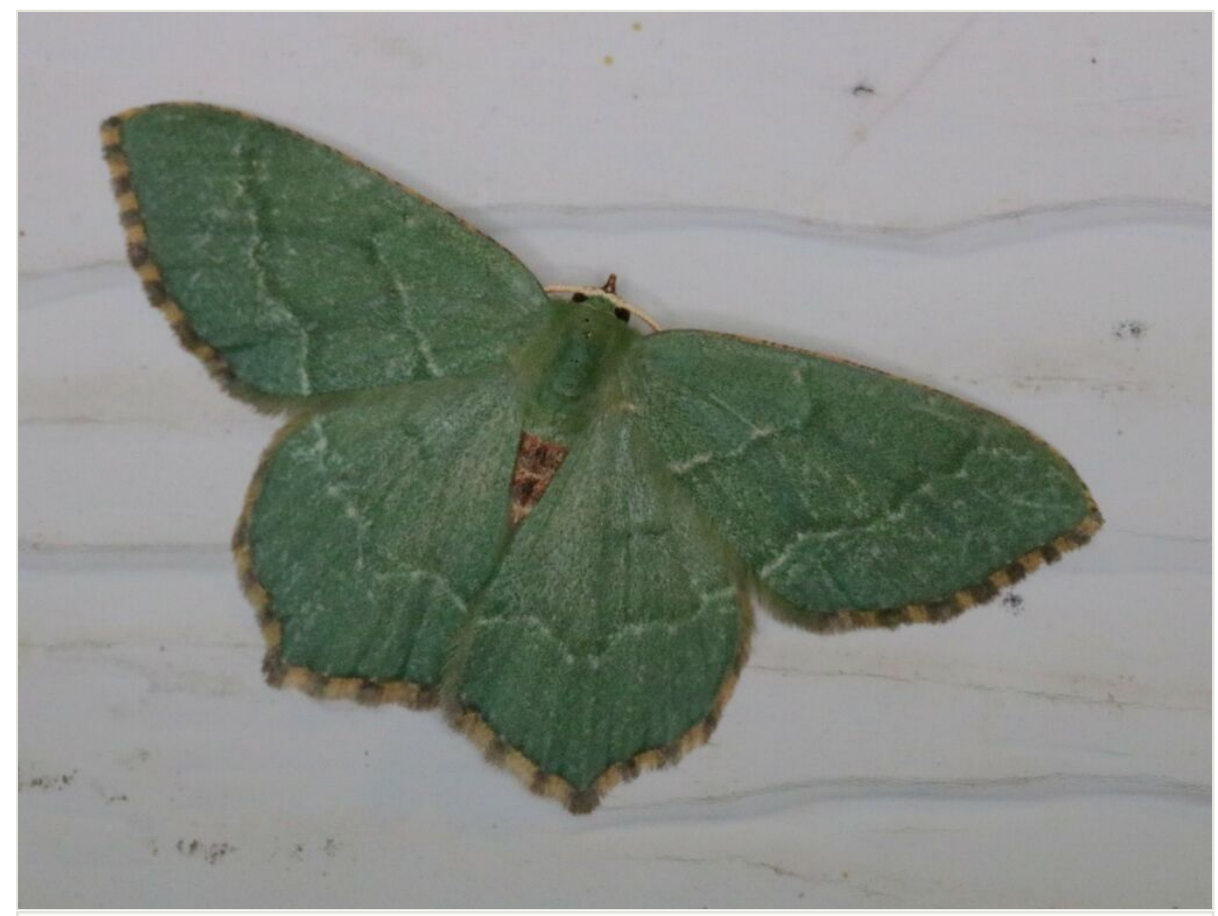

Figure 1. doi

Hemithea aestivaria photographed in Saint-Augustin-de-Desmaures, Québec, on 30 June 2020. Photo credit: Alexandre Anctil.

\section{First records of Hemithea aestivaria for eastern North America}

On 8 July 2019, an adult individual of $H$. aestivaria was photographed in the Durham Region of southern Ontario. During the summer of 2020, adults of $H$. aestivaria were photographed in Toronto, Ontario (June 29), Saint-Augustin-de-Desmaures, Québec (27 June - 24 July; up to three individuals per night) and Halifax, Nova Scotia (14 July - 26 July). These represent the first records for eastern North America (Table 1Figs 1, 2). 


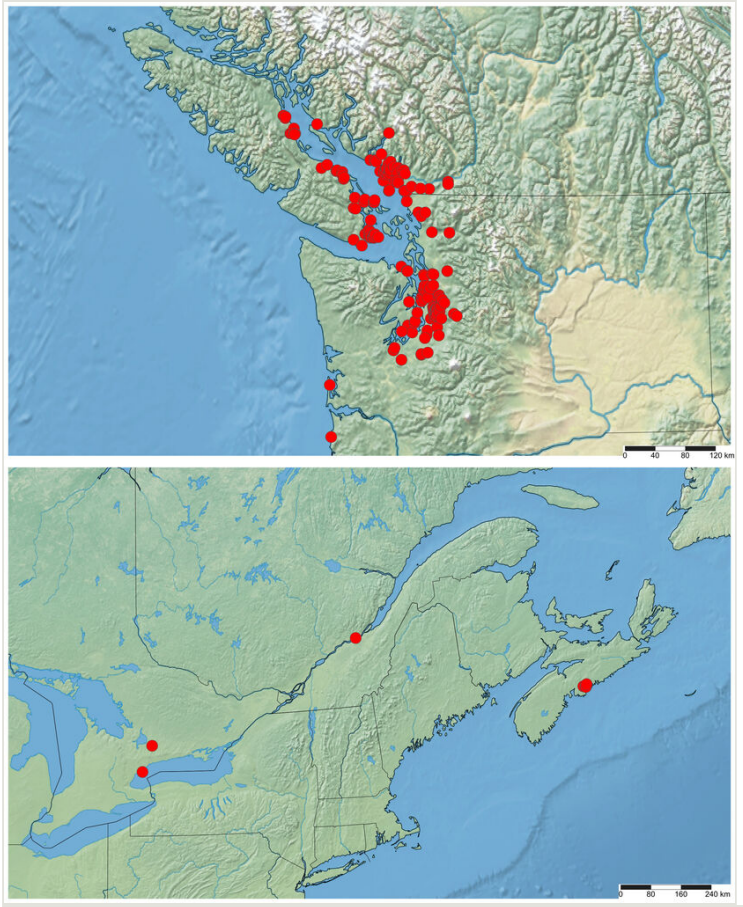

Figure 2. doi

Distribution of Hemithea aestivaria in western (top) and eastern (bottom) North America, based on iNaturalist (www.inaturalist.org) photographic records. Identification of all records were independently verified by the authors and are current to 11 February 2021.

\section{Discussion}

It is unclear if the eastern North American records represent new and temporary introductions or if $H$. aestivaria has been established for a number of years and simply remained undetected at low population densities. Although many iNaturalist observations of Geometridae are now available for the urban regions where $H$. aestivaria was found (> 5000 for Toronto, $>800$ for Quebec City and $>800$ for Halifax, as of Feb 2021), the vast majority of these are for 2018 - 2020. For example, the Moths of Ontario iNaturalist project currently has about 144,000 observations for 2020 , an increase of about $70 \%$ from the previous year (https://www.inaturalist.org/projects/moths-of-ontario/stats). It is therefore possible that $H$. aestivaria has gone undetected for a number of years prior to 2020 . The synchrony in appearance of such widely-disjunct localities in 2020 is noteworthy and is also perhaps best explained by a substantial increase of iNaturalist observers and observations in 2020.

The occurrence of $H$. aestivaria in the Toronto, Québec and Halifax Regions and its absence in relatively well-surveyed adjacent regions, indicates multiple points of introduction, probably via major shipping ports-of-entry along the Atlantic coast and St. 
Lawrence corridor or through aerial transportation. Indeed, the observations from Toronto, Saint-Augustin-de-Desmaures and Halifax are all located within $30 \mathrm{~km}$ of an international airport. Since both larvae and adults are relatively large and short-lived, the most plausible mode of transport is as dormant (overwintering) eggs, which could easily escape detection on fruit tree or ornamental nursery stock. DNA sequencing of eastern populations could shed light on their geogrphic origin.

To our knowledge, no study on the climatic niche of $H$. aestivaria has been conducted. In Europe, it is widespread, but absent from northern Scandinavia and the Mediterranean lowlands (Hausmann 2001). Skou (1986) reported that its distribution was limited to the southernmost coastal parts of Norway, Sweden and Finland and no significant inland range expansion has been noted since then (Global Biodiversity Information Facility 2021). Although its distribution is restricted in northern Europe, $H$. aestivaria is apparently able to tolerate relatively cold winters. Nevertheless, its European distribution, combined with the fact that it has failed to colonise inland British Columbia and Washington beyond very mild coastal regions in almost 50 years after its introduction, suggests that it is unlikely that $H$. aestivaria will expand into interior eastern North America in the near future. However, the species could become more frequent in near-shore regions along the Atlantic coast, St. Lawrence River and Great Lakes, as suggested by its Fennoscandian distribution. The coming years will provide a clearer picture of the colonisation and expansion potential of $H$. aestivaria in eastern North America, particularly with the considerable surveillance potential that citizen scientist platforms, such as iNaturalist, provide. Its spread would be facilitated through transport of dormant fruit trees or nursery stock, as is the case for another introduced geometrid (Maier 2005).

\section{References}

- $\quad$ Bolte K, Munroe EG (1979) Hemithea aestivaria in British Columbia: Characters of a Palearctic genus and species not previously known from North America. The Canadian Entomologist 111: 1121-1126. https://doi.org/10.4039/Ent1111121b-10

- Doganlar M, Beirne BP (1979) Hemithea aestivaria, a geometrid new to North America, established in British Columbia (Lepidoptera: Geometridae). The Canadian Entomologist 111: 1120-1121.

- $\quad$ Ferguson DC (1975) Host records for Lepidoptera reared in eastern North America. Agricultural Research Service, US Department of Agriculture. Publication no 1516.

- Ferguson DC (1978) Pests not known to occur in the United States or of limited distribution. Winter moth Operophtera brumata (L.) Lepidoptera: Geometridae. USDA. Cooperative Plant Pest Report 3: 687-694.

- Ferguson DC (1985) Geometroidea: Geometridae: Geometrinae. Fascicle 18.1. In: Dominick RB, et al. (Ed.) The Moths of America North of Mexico. E.W. Classey, London, 131 pp. [ISBN 0-933003-00-5].

- $\quad$ Gillespie DR, Gillespie BI (1982) A list of plant-feeding Lepidoptera introduced into British Columbia. Journal of the Entomological Society of British Columbia 70: 37-54.

- Global Biodiversity Information Facility (2021) Hemithea aestivaria (Hubner, 1789). www.gbif.org/en/species/1991371. Accessed on: 2021-2-09. 
- Hausmann A (2001) Geometrid moths of Europe. Vol. 1: Introduction to the series. Archiearinae, Oenochrominae, Geometrinae. Apollo Books, Stenstrup. [ISBN 978-87-88-75735-4]

- Maier CT (2005) Hosts, pattern of seasonal emergence and flight, and new distributional records of palearctic Pasiphila rectangulata (Lepidoptera: Geometridae) in the northeastern United States. Annals of the Entomological Society of America 98 (2): 214-218. https://doi.org/10.1603/0013-8746(2005)098[0214:HPOSEA]2.0.CO;2

- Mattson WJ, Niemela P, Millers I, Inguanzo Y (1994) Immigrant phytophagous insects on woody plants in the United States and Canada: an annotated list. USDA. General Technical Report NC-169.

- Pohl GR, Cannings RA, Landry JF, Holden DG, Scudder GG (2015) Checklist of the Lepidoptera of British Columbia, Canada. Entomological Society of British Columbia Occ. Paper, 3. Lulu Publishing

- Pohl GR, Patterson B, Pelham JP (2016) Annotated taxonomic checklist of the Lepidoptera of North America, North of Mexico. https://www.researchgate.net/profile/ Greg_Pohl/publication/302570819 Annotated taxonomic checklist_of the Lepidoptera of North America North of Mexico/links/5731597b08ae100ae557533a/ Annotated-taxonomic-checklist-of-the-Lepidoptera-of-North-America-North-ofMexico.pdf. Accessed on: 2021-2-09.

- Pohl GR, Landry JF, Schmidt BC, Lafontaine JD, Macaulay AD, vanNieukerken EJ, DeWaard JR, Dombroskie JJ, Klymko J (2018) Annotated checklist of the moths and butterflies (Lepidoptera) of Canada and Alaska. Pensoft, 580 pp.

- Skou P (1986) The geometroid moths of north Europe (Lepidoptera: Drepanidae and Geometridae). Brill, Leiden.

- University of Alberta E. H. Strickland Entomological Museum (2021) Hemithea aestivaria. https://doi.org/10.18165/9enbmt. Accessed on: 2021-2-08. 